\title{
Substâncias fenólicas, flavonoides e capacidade antioxidante em erveiras sob diferentes coberturas do solo e sombreamentos
}

FERRERA, T.S. ${ }^{*}$; HELDWEIN, A.B. ${ }^{\prime}$; DOS SANTOS, C.O. ${ }^{\prime}$; SOMAVILLA, J.C. ${ }^{\prime}$; SAUTTER, C.K.1

Universidade Federal de Santa Maria (UFSM), Campus Mariano da Rocha Filho, Avenida Roraima, $n^{\circ} 1000$,

Bairro Camobi, CEP: 97105-900, Santa Maria, RS, Brasil. *Autor para correspondência: tsferrera@yahoo.com.br

\begin{abstract}
RESUMO: Objetivou neste trabalho analisar a concentração de polifenóis totais, flavonoides e capacidade antioxidantes por meio dos métodos ABTS e FRAP, em erveiras jovens cultivadas em solo coberto e com sombreamento. Mudas de erva-mate foram submetidas aos tratamentos com solos cobertos e desnudos em sombreamentos de $0,18,35$ e $50 \%$, após sete e onze meses de cultivo, verão e outono, respectivamente. Foram coletadas folhas maduras para realização dos extratos utilizados para as análises de compostos fenólicos por meio da reação de oxirredução com reagente de Folin-Ciocalteu, flavonoides por método colorimétrico e capacidade antioxidante por frente ao radical ABTS e poder de redução do ferro (FRAP). O teor de compostos fenólicos foi maior nos tratamentos com $35 \%$ de sombreamento em comparação ao grupo dos flavonoides e capacidade antioxidante, o que foi demonstrado pela correlação do sombreamento com estes parametros. No método FRAP a maior correlação demonstra que o outono é a melhor época de colheita por apresentar maior concentração de compostos fitoquímicos. Ficou evidente a influência positiva dos sombreamentos (35 e $50 \%$ ) no teor de compostos fenólicos e flavonoides relacionados à capacidade antioxidante e à qualidade da erva-mate para atender ao mercado consumidor.
\end{abstract}

Palavras-chaves: Fitoquímica; Ilex paraguariensis; Planta Climácia; Metabolismo Secundário

\begin{abstract}
Phenolic Substances, Flavonoids, and Antioxidant Capacity in Herbs under Different Soil Covers and Shadings. This study aimed to analyze the concentration of total polyphenols, flavonoids, and antioxidant capacity, by the methods ABTS and FRAP, in young herbs grown in covered and shaded soil. Yerba mate seedlings were subjected to treatment with bare and covered soils in shadings of $0,18,35$, and $50 \%$, after seven and eleven months cultivation, summer and fall, respectively. Mature leaves were collected to perform the analyses of phenolic compounds by redox reaction with Folin-Ciocalteu reagent, of flavonoids by colorimetric method, and of antioxidant capacity by ABTS radical and FRAP (iron reduction method). The content of phenolic compounds was higher in the treatments with $35 \%$ shading in correlation with the group of flavonoids and antioxidant capacity. In the FRAP method, the higher correlation shows that autumn is the best time to harvest because of the higher concentration of phytochemical compounds. The positive influence of shading (35 and 50\%) was evident in the content of phenolic compounds and flavonoids related to antioxidant capacity and better quality of yerba mate to meet the consumer market.
\end{abstract}

Keywords: Phytochemistry; Ilex paraguariensis; Climax Plant; Secondary Metabolism

\section{INTRODUÇÃO}

A erva-mate (Ilex paraguariensis St. Hil.) da família botânica Aquifoliaceae é uma planta arbórea nativa do Sul e Centro-Oeste brasileiro, norte Argentino e Paraguai. A utilização pelos povos nativos indígenas da região sul-americana foi adaptada pelos colonizadores europeus na forma de bebidas quentes como o "chimarrão" e chás, ou frias, da qual se destaca o "tererê", ambos feitos das folhas e ramos finos da erva-mate. O costume de beber chimarrão ou tererê está arraigado na cultura e tradição em grande parte da população da região de sua origem e no Uruguai.

Segundo o Banco de Dados Agregados do IBGE (2014), no Brasil, em 2012, foram produzidas 513.256 toneladas de erva-mate verde, em 76 mil hectares, resultando em uma produção média de

Recebido para publicação em 13/10/2015

Aceito para publicação em 05/08/2016

10.1590/1983-084X/15_197

Rev. Bras. PI. Med., Campinas, v.18, n.2, supl. I, p.588-596, 2016. 
6,7 t ha-1. Conforme Jaboinski (2003) a produção está diretamente relacionada à tecnologia adotada na implantação e no manejo dos ervais. Além disso, destaca-se que a cultura da erva mate gera cerca de 710 mil empregos diretos e que seu cultivo é desenvolvido em mais de 180 mil propriedades rurais de 596 municípios do Brasil, mais especificamente da região Sul em pequenas e médias propriedades, demonstrando sua importância social e econômica (Embrapa, 2005). Nas regiões produtoras e beneficiadoras a atividade constitui-se numa das principais opções de ocupação, emprego e renda no meio rural, especialmente nos meses de junho, julho e agosto, época da concentração da colheita (Embrapa, 2005) e de menor disponibilidade de trabalho em outras atividades agrícolas.

O clima, o tipo de cultivo, o manejo e a origem da progênie afetam a composição da erva-mate. Grande número de compostos químicos ativos têm sido identificados em biomassa comercial e em seus extratos, dos quais vários podem ser benéficos à saúde. Dois grupos de compostos são mais elevados: os polifenóis (ácidos clorogênicos como: ácidos clorogênicos, ácido cafeico; ácido 3,4-dicafeoilquínico; ácido 3,5-dicafeoilquínico e ácido 4,5-dicafeoilquínico) e as xantinas (cafeína e teobromina), seguido pelo subgrupo de polifenóis flavonoides (quercetina, canferol e rutina), aminoácidos, minerais ( $\mathrm{P}, \mathrm{Fe}$ e $\mathrm{Ca}$ ) e vitaminas, principalmente dos complexos $\mathrm{C}$, B1 e B2 (Dartora, 2010).

Nos vegetais, os compostos fitoquímicos são produtos naturais, conhecidos como metabólitos secundários, apresentando funções ecológicas importantes como proteção contra herbívoros e patógenos, ação alelopática, além de agir como atrativos para animais polinizadores (Larcher, 2004; Taiz \& Zeiger, 2013).

Segundo Escalada et al. (2011) os compostos presentes na erva-mate estão diretamente relacionados ao cultivo e processamento da matéria prima. Segundo Rossa (2013), os compostos fenólicos pertencem a uma classe de substâncias químicas que podem ser de estruturas simples e complexas, derivadas dos aminoácidos fenilalanina e da tirosina, que possuem em sua estrutura química pelo menos um anel aromático com um ou mais grupamentos hidroxilas $(-\mathrm{OH})$. Os compostos fenólicos podem se dividir em flavonoides (antocianinas, flavonóis; e isoflavonas) e não flavonoides (ácidos fenólicos).

Os compostos fenólicos pertencentes aos vegetais são encontrados com estruturas variadas, como os ácidos fenólicos, derivados da cumarina, taninos e flavonoides, que podem atuar como agentes redutores, sequestrantes de radicais livres, quelantes de metais ou desativadores do oxigênio singleto (Larcher, 2004; Taiz \& Zeiger, 2013). Atualmente, os compostos fenólicos tem se tornado compostos de grande interesse, devido suas propriedades benéficas a saúde, sendo alvo de muitos estudos (Taiz \& Zeiger, 2013; Rossa, 2013). Segundo Ferreira et al. (2011) os antioxidantes da erva-mate também tem sido alvo de pesquisas, por substituição dos antioxidantes sintéticos por extratos de plantas, os chamados antioxidantes naturais. Segundo os órgãos de saúde pública como OMS a utilização extensiva de antioxidantes sintéticos e sua ingestão prolongada pode ser associado com aparecimento de doenças. A pesquisa por antioxidantes naturais é uma nova tendência de mercado fármaco e industrial, pois, além de manter as propriedades organolépticas e químicas de alimentos, também são associados a manutenção de saúde e prevenção de doenças.

Segundo Canterle (2005) a atividade antioxidante das plantas de erva-mate ( $I$. paraguariensis) é maior que em outras espécies do gênero llex spp., a mesma também é preservada no chimarrão e tererê, devido a planta apresentar altos teores de ácidos cafeicos, cafeoil e outros compostos.

Conforme Rossa (2013) tanto, os compostos fenólicos, quanto a atividade antioxidante apresentam uma gama de efeitos biológicos, incluindo ação antioxidante, antimicrobiana, antiinflamatória e vasodilatadora. Os benefícios são atribuídos ao consumo da infusão de erva-mate, que atua como antioxidante no organismo humano, sendo oxidado em preferência a outros constituintes do alimento ou componentes celulares e tecidos (Rossa, 2013).

Quanto à erva-mate alguns trabalhos científicos já contribuíram para o conhecimento da fenometria e ecofisiologia da planta, bem como da sua adaptação a diferentes microclimas e as influências meteorológicas na erva-mate (Suertegaray, 2002; Foltran, 2005; Mazuchowski et al., 2007; Caron et al., 2014a b). Porém, são poucos os trabalhos relacionando as condições meteorológicas e micrometeorológicas aos compostos fitoquímicos em erveiras, estando os trabalhos mais relacionados de forma genérica ao armazenamento (Rachwal et al., 2002, Suertegaray, 2002; Donaduzzi et al., 2000, Canterle, 2005, Heck et al., 2008, Dutra et al., 2010, Dartora, 2010, Escalada et al., 2011, Ferreira et al., 2011, Rossa, 2013).

Este trabalho objetivou analisar o teor de compostos fenólicos, flavonoides, e a capacidade antioxidante por meio dos métodos de captura do radical ABTS e através do poder de redução do ferro FRAP, em erveiras jovens cultivadas em solo coberto e com sombreamento. 


\section{MATERIAL E MÉTODOS}

O experimento foi conduzido no Departamento de Fitotecnia, da Universidade Federal de Santa Maria em Santa Maria, RS ( $29^{\circ} 42^{\prime}$ 23"S; 53 43' 15"W; 95 m). Segundo a classificação de Köppen que se baseia, principalmente, nas características térmicas e na distribuição sazonal da precipitação pluvial, o munícipio de Santa Maria tem clima Subtropical Cfa, ou seja, com valores normais de chuva regularmente distribuídas no ano com precipitação média anual de $1712,9 \mathrm{~mm}$ e temperaturas do ar do mês mais quente superiores a $22^{\circ} \mathrm{C}$, tendo temperatura média anual de $19^{\circ} \mathrm{C}$ (Wrege et al., 2011).

As mudas de erva-mate da matriz Cambona foram transplantadas em 15 de maio de 2013, sendo a área experimental formada por 32 canteiros com dimensões de $3,10 \mathrm{~m} \times 1,70 \mathrm{~m}$. O espaçamento usado entre linhas e entre plantas foi de $0,55 \mathrm{~m}$, totalizando 12 plantas por parcela. $O$ delineamento foi o inteiramente casualizado, os tratamentos constaram de sombreamento com tela plástica de $18 \%, 35 \%$ e $50 \%$ mais o tratamento a pleno sol $(0 \%)$, com e sem cobertura de solo, sendo 8 tratamentos totalizando 32 parcelas.

Em cada uma das parcelas foi montado uma estrutura de sustentação a $1,0 \mathrm{~m}$ de altura. Para isso foi preparada uma estrutura com estacas de madeira e arame liso esticado horizontalmente, que serviram para sustentar a tela plástica com sombreamento. A tela plástica recobriu toda parte superior das parcelas, bem como toda a lateral do lado norte e oeste, de modo a evitar a incidência direta de radiação solar.

A cobertura do solo foi renovada a cada quatro meses deixando-se uma camada com espessura média de $3 \mathrm{~cm}$ de restos vegetais. Foram realizadas duas avaliações dos compostos, uma no verão (dezembro/2013) e outra no outono (abril/2014). As folhas maduras de erva-mate foram coletadas no final de dezembro de 2013 (verão) e em abril de 2014 (outono) e foram avaliadas em relação ao teor de compostos fenólicos, flavonoides e quanto a capacidade antioxidante in vitro, a partir da obtenção dos extratos.

Os extratos foram obtidos de folhas adultas (maturas) de erva-mate de cada planta do experimento. Foram coletadas 20 folhas de ervamate por tratamento, em individuos da área útil. Após a coletada, as folhas foram congelas com nitrogênico líquido e acondicionadas em frezzer. Para a obtenção dos extratos as amostras de ervamate foram secas em estufa com circulação forçada de $\operatorname{ar}\left(55^{\circ} \mathrm{C} / 24\right.$ horas $)$ e trituradas em micromoinho refrigerado (Marconi ${ }^{\circ}$, modelo MA630) com tamanho de partícula inferior a $1 \mathrm{~mm}$.

Para obtenção dos extratos foi realizado um pré-teste de diluições para se verificar a melhor extração dos compostos, utilizando-se os solventes etanol:água destilada nas proporções de: $10: 90 \mathrm{v} / \mathrm{v}$; 20:80 v/v; 60:40 v/v e 80:20 v/v (Tabela 1). O uso do solvente etanólico 20:80 v/v em ultrassom apresentou maior eficiencia na extração, sendo utilizado neste trabalho (Tabela 1). Os extratos foram preparados na proporção de 1:50 (p/v) amostra:solvente. As extrações foram realizadas em banho ultrassônico com frequência de $40 \mathrm{KHz}$ (Ultra Sonic Clean, modelo USC 1600) por 15 minutos à temperatura ambiente $\left(21^{\circ} \mathrm{C} \pm 2^{\circ} \mathrm{C}\right)$. Os extratos foram filtrados em papel filtro e acondicionados em eppendorfs, devidamente identificados, e estocados $\mathrm{a}-18^{\circ} \mathrm{C}$ até o momento das análises.

A quantificação dos compostos fenólicos totais em cada extrato foi determinada por espectrofotometria, por meio da reação de oxirredução com reagente de Folin-Ciocalteu, o qual reage com as hidroxilas presentes nos polifenóis, segundo a metodologia descrita por Singleton \& Rossi (1965).

Neste procedimento, o extrato foi diluído em solução extratora alcoólica acidificada, etanol:água: $\mathrm{HCl}(70: 30: 1)$, a seguir foi pipetado em tubo de ensaio, $200 \mu \mathrm{L}$ do extrato diluído, $1000 \mu \mathrm{L}$ do reagente de Folin-Ciocalteu $\left(1: 10 \mathrm{H}_{2} \mathrm{O}\right)$ e $800 \mu \mathrm{L}$ de solução de carbonato de sódio $\left(\mathrm{Na}_{2} \mathrm{CO}_{3}\right) 7,0 \%$.

As leituras foram realizadas em triplicata das absorbâncias em espectrofotômetro UV-visível (HOMIS SF 200DM) em comprimento de onda de $765 \mathrm{~nm}$, agitadas e permanecerem em repouso, ao abrigo da luz, por duas horas em temperatura ambiente. O cálculo do teor de compostos fenólicos foi determinado por interpolação da absorbância das amostras contra uma curva de calibração construída com padrão de ácido gálico, nas concentrações de 0 ; $10 ; 20 ; 30 ; 40,50,60,70$ e $80 \mathrm{mg} \mathrm{L}^{-1}$. Os resultados foram expressos em miligrama de equivalentes de

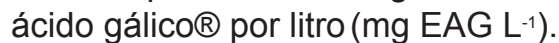

$O$ teor de flavonoides foi analisado pelo

TABELA 1. Teores de compostos fenólicos totais de diferentes extratos etanólicos de erva-mate (Ilex paraguariensis St. Hill.) submetidos ao ultrassom

\begin{tabular}{cc}
\hline $\begin{array}{c}\text { Extrações etanólicas } \\
\text { com ultrassom (\%) }\end{array}$ & $\begin{array}{c}\text { Compostos Fenólicos } \\
\text { (mg EAG L-1) }\end{array}$ \\
\hline 0 & $306,7 \mathrm{~b}$ \\
10 & $353,4 \mathrm{a}$ \\
20 & $333,9 \mathrm{ab}$ \\
60 & $331,2 \mathrm{ab}$ \\
80 & $245,8 \mathrm{c}$ \\
\hline
\end{tabular}

Letras minúsculas diferentes correspondem a diferenças significativas entre os diferentes extratos etanólicos, pelo teste de Tukey $(p \leq 0,05) n=9$. 
método colorimétrico descrito por Zhishen, et al. (1999).

Alíquotas de $1 \mathrm{~mL}$ dos extratos diluídos obtidos das folhas que foram adicionadas em balão volumétrico de $10 \mathrm{~mL}$ contendo $4 \mathrm{~mL}$ de água destilada. No tempo zero, foi adicionado ao balão volumétrico $0,3 \mathrm{~mL}$ de $\mathrm{NaNO}_{2} 5 \%$. Após cinco minutos adicionou-se $0,6 \mathrm{~mL}$ de $\mathrm{AlCl}_{3} 10 \%$. Seis minutos depois, foi adicionado $2 \mathrm{~mL}$ de $\mathrm{NaOH} 1 \mathrm{M} \mathrm{e}$ o volume completado até $10 \mathrm{~mL}$ com água destilada.

As leituras das amostras foram realizadas em triplicata das absorbâncias em espectrofotômetro UV-visível (HOMIS SF 200DM) em comprimento de onda de $510 \mathrm{~nm}$. O teor de flavonoides foi determinado utilizando-se uma curva padrão de catequina (0-250 $\left.\mathrm{mg} \mathrm{L}^{-1}\right)$ e os resultados, determinados a partir de uma equação de regressão, expressos em miligramas de equivalentes de catequina por litro (mg ECA L-1).

Para a determinação da capacidade antioxidante total pelo método de redução do ferro (FRAP) foi utilizado o procedimento descrito por Benzie \& Strain (1996). Este ensaio se baseia na medida direta de habilidade dos antioxidantes (redutores) da amostra em reduzirem, em meio ácido (pH 3,6), o complexo $\mathrm{Fe}^{3+} /$ tripiridiltriazina (TPTZ), para formar $\mathrm{Fe}^{2+}$, de intensa cor azul e absorção máxima a $593 \mathrm{~nm}$.

No ensaio FRAP, soluções de tampão acetato, $\mathrm{FeCl}_{3} \cdot 6 \mathrm{H}_{2} \mathrm{O} 20 \mathrm{mM}$ e TPTZ $(10 \mathrm{mM})$ foram adicionadas na proporção 10:1:1, originando 0 reagente FRAP. As amostras dos extratos de erva-mate foram diluídas em água destilada, a seguir, alíquotas $(0,2 \mathrm{~mL})$ de cada extrato foram misturadas com $1,8 \mathrm{~mL}$ do reagente FRAP e a absorbância da mistura de reação medida a 593 nm em espectrofotômetro UV-visível (HOMIS SF 200DM), após incubação em banho-maria a $37^{\circ} \mathrm{C}$ durante $30 \mathrm{~min}$. O Trolox ( $1 \mathrm{mM}$ ) foi utilizado como padrão para construir uma curva de calibração, nas concentrações de $0 ; 0,025 ; 0,05 ; 0,075$; $0,100,0,150,0,200$ e 0,250 mM de Trolox sendo os resultados expressos em mM TROLOX L-1 (capacidade antioxidante equivalente ao Trolox).

Para a determinação da atividade antioxidante pelo método do radical ABTS $\bullet+$, utilizou-se a metodologia descrita por $\mathrm{Re}$ et al., (1999). Inicialmente, foi formado o radical ABTS•+, a partir da reação de $14 \mathrm{mM}$ de ABTS com 4,9 mM de persulfato de potássio $(1: 1 \mathrm{v} / \mathrm{v})$, os quais foram incubados à temperatura ambiente e na ausência de luz, por 16 horas. Transcorrido esse tempo, a solução foi diluída em etanol até a obtenção de uma solução com absorbância de 0,680 a 0,720 $(0,700 \pm 0,02)$.

Para realizar as análises, foram adicionados em tubos de ensaio a solução contendo o radical
ABTS •+ e o extrato diluído em etanol. A absorbância foi monitorada em espectrofotômetro UV-visível (HOMIS SF 200DM) a $750 \mathrm{~nm}$, após 15 minutos de reação.

Uma curva de calibração foi construída, utilizando-se como solução-padrão o antioxidante sintético Trolox nas concentrações de 0; 0,025; 0,$05 ; 0,075 ; 0,100$ e 0,150 mM em etanol. Todas as leituras foram realizadas em triplicata, e os resultados expressos em $\mathrm{mM}$ de Trolox por litro ( $\mathrm{mM}$ TROLOX L-1) (capacidade antioxidante equivalente ao Trolox).

Os dados das avaliações do experimento foram testados quanto à normalidade, homogeneidade e independência, procedendo-se a transformação dos dados para Ln (logaritmo neperiano) quando necessário. Realizou-se então a Análise da Variância (ANOVA), teste de Tukey a $5 \%$ para comparação de médias e correlação de Person $\left(r_{p}\right)$ entre as análises de compostos (Ferreira, 2008). As análises estatísticas foram realizadas com software SISVAR 5.3 e BioEstat 5.0 .

\section{RESULTADOS E DISCUSSÃO}

As análises fitoquímicas do teor de polifenóis totais, flavonoides e capacidade antioxidante, realizadas na estação: verão, dezembro de 2013 e outono em abril de 2014, mostraram haver efeito dos tratamentos de sombreamento aplicados na composição das folhas das erveiras (Tabela 2).

A maior média de teor de polifenóis na estação do verão foi obtida nas erveiras em solos cobertos e com sombreamento de $50 \%(81,75 \mathrm{mg}$ EAG $L^{-1}$ ), sendo estatisticamente igual ao tratamento com solo coberto e com sombreamento de $35 \%$, enquanto que em solo desnudo e com $0 \%$ de sombreamento, ou seja, a pleno sol apresentou uma concentração reduzida (Tabela 2).

Conforme Donaduzzi et al. (2000) a constituição química da erva-mate apresenta dentre outros compostos fenólicos, ácidos fenólicos e flavonoides, afirmando que os flavonoides são compostos que sofrem pouca variação estrutural e relacionam-se principalmente à quercetina livre e seus derivados glicosilados, além da presença de canferol, mas não associam essas respostas às condições ambientais. No atual trabalho não foi possível avaliar a concentração de kaemferol e de quercetina livre e seus derivados; no entanto, foi possível estudar os flavonoides totais onde os resultados foram similares aos de Donaduzzi et al. (2000).

No outono, a maior média para polifenóis totais foi verificada para solo desnudo e com 35\% de sombreamento $\left(150,35\right.$ mg EAG L $\left.{ }^{-1}\right)$ e a menor 
TABELA 2. Teores de polifenóis totais, flavonoides e capacidade antioxidante em plantas jovens de erva-mate com e sem cobertura de palha sobre o solo em diferentes níveis de sombreamento. Santa Maria, RS, 2015.

\begin{tabular}{|c|c|c|c|c|}
\hline \multirow{2}{*}{$\begin{array}{c}\text { Concentração } \\
\text { do solvente e } \\
\text { tratamentos }\end{array}$} & \multicolumn{2}{|c|}{ Polifenóis totais (mg EAG L-1) } & \multicolumn{2}{|c|}{ Flavonoides (mg ECA L-1) } \\
\hline & $\begin{array}{c}\text { Verão } \\
\text { (Dez/2013) }\end{array}$ & Outono (Abr/2014) & $\begin{array}{c}\text { Verão } \\
\text { (Dez/2013) }\end{array}$ & $\begin{array}{c}\text { Outono } \\
\text { (Abr/2014) }\end{array}$ \\
\hline C'SO\% & $54,03 \mathrm{~cd}$ & $126,92 a b$ & $38,90 \mathrm{~cd}$ & $132,64 \mathrm{c}$ \\
\hline $\mathrm{D}^{2} \mathrm{~S} 0 \%^{3}$ & $40,80 \mathrm{~d}$ & $76,22 \mathrm{c}$ & $30,91 \mathrm{~d}$ & $88,87 \mathrm{c}$ \\
\hline CS18\% & $59,12 \mathrm{bcd}$ & $114,06 \mathrm{abc}$ & $46,80 \mathrm{bc}$ & $115,43 \mathrm{c}$ \\
\hline DS18\% & $67,21 \mathrm{abc}$ & $102,98 \mathrm{bc}$ & $62,45 a$ & $110,56 \mathrm{c}$ \\
\hline $\begin{array}{l}\text { CS35\% } \\
77,33 \mathrm{ab}\end{array}$ & & 145,26 a & $58,79 a b$ & 286,04 a \\
\hline DS35\% & $53,41 \mathrm{~cd}$ & $150,35 \mathrm{a}$ & $55,28 a b$ & $243,12 a b$ \\
\hline CS50\% & $81,75 \mathrm{a}$ & $138,37 a b$ & 62,98 a & $207,51 \mathrm{~b}$ \\
\hline \multirow[t]{3}{*}{ DS50\% } & $64,95 \mathrm{abc}$ & $101,62 \mathrm{bc}$ & $52,65 \mathrm{~b}$ & $94,57 \mathrm{c}$ \\
\hline & \multicolumn{2}{|c|}{$\mathrm{ABTS}^{4}(\mathrm{mM} \text { TROLOX L-1 })^{4}$} & \multicolumn{2}{|c|}{$\mathrm{FRAP}_{5}(\mathrm{mM}$ TROLOX L-1) } \\
\hline & $\begin{array}{c}\text { Verão } \\
\text { (Dez/2013) }\end{array}$ & $\begin{array}{c}\text { Outono } \\
\text { (Abr/2014) }\end{array}$ & $\begin{array}{c}\text { Verão } \\
\text { (Dez/2013) }\end{array}$ & $\begin{array}{c}\text { Outono } \\
\text { (Abr/2014) }\end{array}$ \\
\hline $\mathrm{C}^{2} \mathrm{~S} 0 \%$ & $0,54 \mathrm{~cd}$ & $0,83 a$ & $0,57 \mathrm{c}$ & $2,72 \mathrm{c}$ \\
\hline $\mathrm{D}^{3} \mathrm{~S} 0 \%^{3}$ & $0,49 d$ & $0,73 a$ & $0,52 \mathrm{c}$ & $1,18 d$ \\
\hline CS18\% & $0,61 \mathrm{bc}$ & $0,82 a$ & $0,65 b c$ & $1,64 \mathrm{~d}$ \\
\hline DS18\% & $0,69 a b$ & 0,84 a & $0,82 a b$ & $1,62 \mathrm{~d}$ \\
\hline CS35\% & $0,74 a$ & $0,89 a$ & $0,95 a$ & $4,35 \mathrm{ab}$ \\
\hline DS35\% & $0,61 \mathrm{bc}$ & $0,87 \mathrm{a}$ & $0,70 \mathrm{bc}$ & $5,10 a$ \\
\hline CS50\% & $0,69 a b$ & $0,91 \mathrm{a}$ & $0,93 a$ & $3,20 \mathrm{bc}$ \\
\hline DS50\% & $0,62 \mathrm{bc}$ & $0,70 \mathrm{a}$ & $0,81 a b$ & $1,42 d$ \\
\hline
\end{tabular}

${ }^{1}$ cobertura de solo e ${ }^{2}$ solo desnudo, ${ }^{3}$ percentual de sombreamento, ${ }^{4}$ Ácido 2,2'-azino-bis (3-etilbenzotiazolin) 6-ácido sulfônico) e ${ }^{5}$ Ferric Reducing Antioxidant Power. Letras minúsculas diferentes na mesma coluna correspondem a diferenças significativas entre os tratamentos de mesma concentração do solvente, pelo teste de Tukey $(p<0,05) n=3$.

média foi de 76,22 mg EAG L-1 para a condição de solo desnudo e a pleno sol (Tabela 2). Os resultados apresentados pelo Teste de Tukey a 5\% demonstram que o acúmulo de compostos fenólicos é maior nos tratamentos com maior sombreamento destacandose o sombreamento a $35 \%$ de modo geral, sendo que na estação do outono o acumulo de compostos é maior que no verão (Tabela 2). O que corrobora com a época de colheita no RS para os ervais nativos (Daniel, 2009).

Evidenciando-se que um pequeno estresse gerado pela radiação solar é suficiente para produzir metabólitos secundários $(126,92 \mathrm{mg}$ EAG $\mathrm{L}^{-1}$ ) com sombreamento de $0 \%$ (pleno sol), no outono (Tabela 2). Porém, esse estresse quando intensificado nas condições de verão $(54,03 \mathrm{mg}$ EAG L-1) com sombreamento de $0 \%$ (pleno sol) a indica que degradação dos compostos fenólicos é maior comparada com o outono, por isso não sendo acumulando nas folhas maduras. Suertegaray (2002) ao analisar a composição físico-química da erva-mate de plantas adultas, verificou aumento na concentração de compostos fenólicos no período de verão no sistema agroflorestal onde o sombreamento é maior que em monocultivos. Diferentemente do observado no experimento 1, em plantas jovens, aonde o sombreamento de $35 \%$ no verão e outono se obteve maior concentração dos compostos do que a pleno sol, principalmente na estação do outono. Suertegaray (2002) para ervamate e Larcher (2004) e Taiz \& Zeiger (2013) nas plantas em geral para diferentes espécies, relatam que o aumento da radiação solar ou a sua diminuição pode ser benéfica às plantas, dependendo da 
fenofase do vegetal. No caso das erveiras jovens do presente trabalho, o aumento da radiação solar, da temperatura do ar e temperatura das folhas na estação de maior demanda atmosférica (verão), mostram que o sombreamento de $35 \%$ a $50 \%$ são os melhores para o acumulo de compostos fenólicos quando a planta de erva-mate ainda é mais frágil e está na fase juvenil.

As altas temperaturas em torno de 35 a $40^{\circ} \mathrm{C}$, mensuradas no experimento, nos meses de verão influenciam diretamente na concentração de compostos fenólicos, pois quanto maior a temperatura em torno dos $35-40^{\circ} \mathrm{C}$ maior será a degradação ou inativação de enzimas e/ou proteínas inibindo o metabolismo (Larcher, 2004; Taiz \& Zeiger, 2013). Outro fator que deve ser considerado em relação a concentração de polifenóis é que o aumento da radiação solar induz o fechamento estomático aumentando a concentração intercelular de dióxido de carbono. Conforme Bertagnolli et al. (2007), em uvas, observaram que concentração elevadas de dióxido de carbono no meio celular inibe a síntese de compostos fenólicos, pois para formação de tais compostos é necessária a liberação de $\mathrm{CO}_{2}$. Isso explica a preferência dos consumidores por uma erva-mate mais suave, que geralmente são de sistema agroflorestal, que permite uma incidência de radiação solar de menor intensidade. Suertegaray (2002) relata que em plantas adultas de erva-mate a pleno sol, em diferentes microclimas produziu-se valores discrepantes dos principais compostos em decorrência das peculiaridades do microclima onde as plantas se encontravam: monocultivos e sistemas agroflorestais.

A composição fenólica em plantas de erva-mate já foi estudada por diversos autores, como, Rachwal et al. (2002), Suertegaray (2002); Donaduzzi et al. (2000), Dutra et al. (2010), Escalada et al.(2011) e Rossa (2012), dos quais poucos a relacionam com o ambiente de produção encontrando-se resultados concordantes e conflitantes com os atuais. No experimento 1, o uso da tela de sombreamento demonstrou resultados mais coerentes, associando-se as concentrações de polifenóis e flavonoides (Tabela 2). No caso das erveiras jovens, em fase de adaptação às condições de campo, o sombreamento de $35 \%$ no outono apresenta-se mais eficaz para produção de compostos fenólicos, em plantas adultas como Rachwal et al. (2002) encontraram diferenças nos teores de polifenóis, havendo correlação positiva do teor de polifenóis nas plantas na condição de outono relacionado à luminosidade.

Em erveiras adultas Escalada et al. (2011) avaliaram o efeito da época de colheita que influenciou no conteúdo de compostos fenólicos independentemente da origem e do tipo de secagem a que foram submetidas às folhas verdes. Verificaram que nas primeiras, as colheitas próximas ao outono possuem maior concentração de compostos fenólicos, assim como em plantas jovens de erva-mate, que, como demonstrado no experimento 1 do atual trabalho, no verão tiveram concentração dos compostos fenólicos menor do que no outono.

$\mathrm{Na}$ avaliação geral conjugada dos resultados (Tabela 2 ), sobressai o fato importante de que nos melhores tratamentos de outono (35\% de sombreamento) o teor de flavonoides é cerca de 4,5 vezes maior do que nos mesmos tratamentos no verão e que o cultivo a pleno sol, ou com sombreamento insuficiente, no outono e principalmente no verão desfavorece a produção de polifenóis, especialmente dos flavonoides, o que pode ser consequência de possíveis estresses causados por alta temperatura, além da exposição a radiação solar excessiva. Também se verifica que no outono o sombreamento de $50 \%$ tende a ser o limite de sombreamento a partir do qual pode ocorrer redução no teor desses compostos na medida em que se aproxima o inverno.

Em uma revisão sobre os fatores que influenciam o teor de metabólitos secundários em plantas medicinais, Gobbo-Neto \& Lopes (2007) relatam que no geral existe associação positiva entre intensidade de radiação solar e produção de compostos fenólicos, dentre os quais se enquadram os flavonoides, taninos e antocianinas, porém não especificam sob que condição climática, época do ano ou região isso é válido, o que dificulta a comparação com os dados obtidos. O que se evidencia pelos dados de radiação solar, medidos durante o período do experimento 1 no verão e do outono é que especificamente para a erva-mate nos primeiros anos de cultivo a resposta não é a mesma que a apregoada por Gobbo-Neto \& Lopes (2007) para fitoterápicos, sendo necessário um nível intermediário de radiação solar para maximizar a produção de polifenóis totais e flavonoides e que a radiação solar intensa diminui a concentração desses compostos secundários.

Segundo Daniel (2009) a atividade antioxidante em erveiras é considerada maior que em outras espécies do gênero /lex spp., sendo que capacidade antioxidante (CA) da mesma é preservada em suas bebidas como o chimarrão e tererê, devido a planta apresentar altos teores de ácidos cafeicos, cafeoil e de outros compostos (Canterle, 2005). Os resultados da CA obtidos (Tabela 2) são relevantes no sentido de nortear técnicas de manejo de produção, visando obter melhor qualidade da produção de erva-mate em plantas jovens. Isso se ressalta, principalmente por que o manejo deverá ser o mesmo para obter melhor 
qualidade em termos de composição em flavonoides e compostos fenólicos totais uma vez que os respectivos resultados apresentaram tendência similar relativa aos tratamentos de sombreamento e cobertura de palha sobre o solo aplicados no experimento 1 (Tabela 2).

Segundo Pereira \& Cardoso (2012) a CA é conferida pelos peroxissomos, com a ação de enzimas (catalase, peroxidase, superóxido dismutase) e também um conjunto heterogêneo de substâncias formado por pigmentos naturais, fenóis, carotenoides, e outros compostos vegetais. Tais substâncias bloqueiam o efeito danoso dos radicais livres, formados nas reações metabólicas ou por fatores externos a planta, os quais são denominados elicitores abióticos (radiação solar, temperatura do ar e estrese hídrico). A geração de radicais livres é normalmente equilibrada pela ação dos antioxidantes endógenos. Então, nas erveiras jovens do experimento 1 é possível perceber que a homeostase das atividades fisiológicas é melhor com a cobertura vegetal do solo e sombreados parcialmente de 35 a $50 \%$, em épocas de maior estresse como verão.

$A$ análise da $C A$ pode ser mensurada pelas técnicas de ABTS, ácido 2,2'-azino-bis (3-etilbenzotiazolin) 6-ácido sulfônico e FRAP (Ferric Reducing Antioxidant Power) (Tabela 2). Para as amostras coletadas no período de outono, a técnica de ABTS não diferenciou os efeitos dos tratamentos, obtendo-se apenas valores com a tendência verificada com a utilização da técnica de FRAP. A técnica de FRAP é mais específica do que a ABTS para erva-mate, pois se consegue discriminar os tratamentos. Houve correlação da técnica de FRAP para polifenóis e para flavonoides no presente estudo.

Em relação à atividade antioxidante, analisada pela técnica de FRAP, os valores são maiores nos tratamentos com 35\% de sombreamento na estação do outono, corroborando com os teores de polifenóis totais, sobretudo, dos flavonoides totais (Tabela 2). Já a menor capacidade antioxidante foi verificada no verão, nos tratamentos a pleno sol, independente do solo estar coberto por palha ou desnudo $(0,57$ e 0,52 mM TROLOX L-1). No outono a menor capacidade antioxidante foi verificada nas amostras coletadas nos tratamentos com solo desnudo sem sombreamento e com $50 \%$ de sombreamento $(1,18$ e 1,42 mM TROLOX L-1), respectivamente (Tabela 2). No verão a maior capacidade antioxidante foi obtida com os tratamentos com $35 \%$ e $50 \%$ de sombreamento; no entanto, estes valores são menores que os encontrados nos tratamentos de outono independentemente do sombreamento pelas concentrações elevadas dos compostos fenólicos, especialmente os flavonoides, enquanto os resultados indicam que nessa época o grau de proteção não é suficiente para evitar a redução da

TABELA 3. Matriz de Correlação de Person $\left(r_{p}\right)$ para os compostos teores de polifenóis totais, flavonoides e capacidade antioxidante em plantas jovens de erva-mate com e sem cobertura de palha sobre o solo em diferentes níveis de sombreamento. Santa Maria, RS, 2015.

\begin{tabular}{|c|c|c|c|c|c|c|c|c|}
\hline Compostos & $\begin{array}{l}\text { Polifenois } \\
\text { Verão }\end{array}$ & $\begin{array}{c}\text { Polifenois } \\
\text { Outono }\end{array}$ & $\begin{array}{c}\text { Flavonoides } \\
\text { Verão }\end{array}$ & $\begin{array}{c}\text { Flavonoides } \\
\text { Outono }\end{array}$ & $\begin{array}{l}\text { ABTS }^{1} \\
\text { Verão }\end{array}$ & $\begin{array}{l}\text { ABTS } \\
\text { Outono }\end{array}$ & $\begin{array}{l}\text { FRAP }^{2} \\
\text { Verão }\end{array}$ & $\begin{array}{l}\text { FRAP } \\
\text { Outono }\end{array}$ \\
\hline $\begin{array}{l}\text { Polifenois } \\
\text { Verão }\end{array}$ & $1,00^{*}$ & 0.51 & 0.85 & 0.50 & 0.91 & 0.57 & 0.94 & 0.29 \\
\hline $\begin{array}{c}\text { Polifenois } \\
\text { Outono }\end{array}$ & & 1.00 & 0.55 & 0.88 & 0.54 & 0.82 & 0.49 & 0.91 \\
\hline $\begin{array}{c}\text { Flavonoides } \\
\text { Verão } \\
\text { Flavonoides }\end{array}$ & & & 1.00 & 0.52 & 0.92 & 0.59 & 0.90 & 0.42 \\
\hline $\begin{array}{c}\text { Flavonoides } \\
\text { Outono } \\
\text { ABTS }\end{array}$ & & & & 1.00 & 0.6 & 0.77 & 0.57 & 0.94 \\
\hline $\begin{array}{l}\text { Verão } \\
\text { ABTS }\end{array}$ & & & & & 1.00 & 0.61 & 0.94 & 0.4 \\
\hline $\begin{array}{l}\text { Outono } \\
\text { FRAP }\end{array}$ & & & & & & 1.00 & 0.49 & 0.71 \\
\hline Verão & & & & & & & 1.00 & 0.39 \\
\hline $\begin{array}{l}\text { FRAP } \\
\text { Outono }\end{array}$ & & & & & & & & 1.00 \\
\hline
\end{tabular}

Rev. Bras. Pl. Med., Campinas, v.18, n.2, supl. I, p.588-596, 2016. 
capacidade antioxidante em relação ao outono. Evidencia-se que nas condições de verão quente acima da média normal de temperaturas máximas de Santa Maria (acima dos $35^{\circ} \mathrm{C}$ ), em plantas jovens de erva-mate não só seria necessário aumentar o grau de sombreamento e manter a cobertura de palha no solo, para melhorar a capacidade antioxidante, mas a temperatura muito elevada é um provável fator limitante e importante a considerar em um zoneamento agroclimático para a qualidade da produção.

Segundo Heck \& Mejia (2007) há grande correlação entre a concentração de compostos fenólicos e antioxidantes, assim como observado no Experimento 1 pela correlação de Pearson (Tabela 3). No experimento 1 também pode-se observar esta correlação, onde plantas sombreadas com $35 \%$ obtiveram maior concentração antioxidantes e compostos fenólicos. Entretanto, a pleno sol houve diminuição de antioxidantes. Isso esta diretamente relacionado à busca de qualidade pelo mercado consumidor, conforme relatado por Daniel (2009).

Os compostos fenólicos e flavonoides e a capacidade antioxidante de cada época (verão/ outono) estão altamente correlacionados pela correlação de Person (rp) (Tabela 3).

Isso comprova que os polifenóis totais produzidos são em sua maioria flavonoides que estão associados à capacidade antioxidantes pelos dois métodos de ABTS e FRAP, sendo que a capacidade antioxidante pelo método de FRAP é maior (Tabela 3). Por isso, conclui-se que em relação às erveiras jovens, do experimento 1, o sombreamento parcial de $50 \%$, no verão e $35 \%$ no outono são as melhores recomendações independente da cobertura ou não do solo no outono, e com solo coberto no verão, sendo o outono a melhor época de colheita neste sistema de cultivo.

\section{CONCLUSÃO}

Conclui-se que o acúmulo de compostos fenólicos foi maior no sombreamento de 35\%, sendo que os flavonoides se correlacionam com os compostos fenólicos, bem como com a capacidade antioxidante pelos métodos de ABTS e FRAP.

\section{REFERÊNCIAS}

BERTAGNOLLI, S. M. M. et. al. Influência da maceração carbônica e da irradiação ultravioleta nos níveis de trans-resveratrol em vinhos de uva cabernet sauvignon. Revista Brasileira de Ciências Farmacêuticas, v. 43, p. 71-77, 2007.

BENZIE, I. F. F.; STRAIN, J. J. The ferric reducing ability of plasma (FRAP) as a measure of antioxidant power: The FRAP assay. Analytical Biochemistry, v. 239, n. 1, p. 70-76, 1996.
CANTERLE, L. P. Erva-mate e atividade antioxidante. 2005. 99f. Dissertação (Mestrado em Tecnologia de Alimentos) - Universidade Federal de Santa Maria, Santa Maria.

CARON, B. O. et. al. Biomassa e acúmulo de nutrientes em Ilex paraguariensis. St. Hil. Ciência Florestal, v. 24, n. 2, p. 1-10, 2014a.

CARON, B. O. et. al. Eficiência do uso da radiação solar por plantas Ilex paraguariensis cultivadas sob sombreamento e a pleno sol. Ciência Florestal, v. 24, n. 2, p. 1-9, 2014b.

DANIEL, O. Erva-mate: sistema de produção e processamento industrial / Omar Daniel. $1^{\text {a }}$ ed. Dourados, MS: UFGD ; UEMS, 2009. 288p.

DARTORA, N. avaliação dos polissacarídeos e metabolitos secundários das folhas de ervamate (Ilexparaguariensis) em diferentes estados fisiológicos e de processamento. 2010. $109 \mathrm{f}$. Dissertação (Ciências Bioquímica)-Universidade Federal do Paraná, Curitiba-PR

DONADUZZI, C. M.; COELHO, S. R. M.; CARDOSO JUNIOR, E. L.; GALLO, A. G.; HUPPES, G. K.; KUHN, I. M. V.; SCHICHEL, C. Teores de cafeína, polifenóis totais e taninos em amostras de erva-mate comercializadas na região de Toledo Paraná. In: CONGRESSO SULAMERICANO DA ERVA-MATE, 2.; REUNIAO TECNICA DA ERVA-MATE, 3., 2000, Encantado. Anais.. Porto Alegre: Comissão dos Organizadores; Universidade do Rio Grande do Sul; Fundação Estadual de Pesquisa Agropecuária, 2000. p. 158-161.

DUTRA, F. L. G.; et. al. determinação de compostos fenólicos por cromatografia líquida de alta eficiência isocrática durante estacionamento da erva-mate. Química Nova, v. 33, n. 1, p. 119-123, 2010.

ESCALADA, G.; et. al. Influencia de la zona de cultivo y procesamiento de la yerba mate sobre su contenido de polifenoles totales y capacidad antioxidante. Revista Ciência e Tecnologia, v. 13, n. 15, p. 66-74, 2011.

FERREIRA, D. F. SISVAR: um programa para análise e ensino de estatística. Revista Científica Symposium, v. 6, n. 2, p. 36-41. 2008

FERREIRA, E. L.; SAMPAIO, G. R.; TORRES, E. A. F. da S.; BASTOS, D. H. M. Natural Antioxidant from Yerba Maté (Ilex paraguariensis St. Hil.) Prevents Hamburger Peroxidation, v. 54, n. 4 p. 803-809, 2011.

FOLTRAN, B. N. Efeito de diferentes níveis de intensidade luminosa na produção de mudas de erva-mate (Ilex paraguariensis st. hill). 2005. 82f. Dissertação (Mestrado em Agronomia) - Universidade Federal do Paraná, Curitiba

GOBBO-NETO, L.; LOPES, N. P. Plantas medicinais: fatores de influência no conteúdo de metabólitos secundários. Química Nova, v. 30, n. 2, p. 374-381, 2007.

HECK, C. I.; et. al. Effect of growing and drying conditions on the phenolic composition of mate teas (Ilex paraguariensis). Journal of Agricultural and Food Chemistry. v. 56, p. 8394-8403, 2008.

IBGE-Brasil. Produção da extração vegetal e da silvicultura - 2009. Disponível em: < http://www.ibge. gov.br/home/estatistica/pesquisas/pesquisa_resultados. php?id_pesquisa=45> Acesso em: 23/08/2014.

JABOINSKI, N. J. Avaliação da eficiência produtiva 
da cultura da erva-mate na região do alto Uruguai gaúcho através da utilização de um diagrama de causa e efeito. 2003. 115f. Dissertação (Mestrado em Agronegócio)-Universidade Federal do Rio Grande do Sul, Porto Alegre

LARCHER, W. Ecofisiologia Vegetal. $1^{\text {a }}$ ed. São Carlos: RiMa. 2004. 531p.

MAZUCHOWSKI, J. Z.; et. al. Efeito da luminosidade e da adição de nitrogênio no crescimento de plantas de Ilex paraguariensis st. hil. Revista Árvore, v. 31, n. 4, p. 619-627, 2007.

PEREIRA, R. J.; CARDOSO, M. G. Metabólitos secundários vegetais e benefícios antioxidantes Vegetable secondary metabolites and antioxidants benefits. Journal of Biotechnology and Biodiversity, v. 3, n. 4, p. 146-152, 2012.

RACHWAL, M. F. G.; et al. Influência da Luminosidade sobre a Produção de Massa Foliar e Teores de Macronutrientes, Fenóis Totais, Cafeína e Teobromina em Folhas de Erva-mate. Comunicado Técnico Ministério da Agricultura Pecuária e Abastecimento, v. 81 n. 1 p. 1-5, 2002.

RE, R.; et. al. Antioxidant activity applying an improved ABTS radical cation descolorization assay. Free Radical Biology \& Medicine, v. 26, n. 9-10, p. 1231-1237, 1999.
ROSSA, U. B. Produtividade e compostos foliares de erva-mate sob efeitos de luminosidade e fertilização. 2013, 208f. Tese (Doutorado em Engenharia Florestal)- Universidade Federal do Paraná, Curitiba

SINGLETON, V. L.; ROSSI, J. A. Colorimetry of phenolics with phosphomolybdic- phosphotungstic acid reagents. American Journal of Enology and Viticulture, v. 16, n. 3, p. 144-158, 1965.

SUERTEGARAY, C. E. O. Dinâmica da cultura da ervamate (Ilex paraguariensis St. Hil.) em sistemas agroflorestais e monocultivos. 2002, 49f. Dissertação (Mestrado em Agroecossistemas)-Universidade de Santa Catarina, Florianópolis

TAIZ, L.; ZEIGER, E. Fisiologia Vegetal. 4. ed. Porto Alegre: Artmed. 2013. 820p.

WREGE, M. S.; STEINMETZ, S.; REISSER JÚNIOR, C.; ALMEIDA, I. R. de. (Ed.). Atlas climático da Região Sul do Brasil: Estados do Paraná, Santa Catarina e Rio Grande do Sul.1a ed. Pelotas: Embrapa Clima Temperado; Colombo: Embrapa Florestas, 2011. 333 p.

ZHISHEN, J.; et. al. The determination of flavonoid contents in mulberry and their scavenging effects on superoxide radicals. Food Chemistry, v. 64, p. 555559, 1999. 